\title{
Differential Potency and Breadth of the Same Epitope-Specific CTLs to Inhibit HIV-1 Replication based on TCR Usage
}

\author{
Ting Tu' ${ }^{1,2}$, Xiaohe Zhou ${ }^{1}$, Tao Li ${ }^{1}$, Cong Jin² and Huabiao Chen ${ }^{1 *}$
}

${ }^{1}$ Jiangsu Key Laboratory of Clinical Laboratory Medicine, Jiangsu University School of Medicine, Zhenjiang, China

${ }^{2}$ National HIV/HCV Reference Laboratory, National Center for AIDS/STD Control and Prevention, Chinese Center for Disease Control and Prevention, Beijing, China

\begin{abstract}
Increasing evidence suggests that the immune control of viral replication by HIV-1-specific cytotoxic T lymphocytes (CTLs) is relevant to the selection of human leukocyte antigen (HLA) allele-restricted antigen-specific CTL repertoire. But the underlying factors accounting for CTL functional difference from T cell receptor (TCR) clonal diversity are currently unclear. Here we found that CTL repertoire specific for HLA-B*27-restricted HIV-1 Gag p24 epitope KK10 (KRWIILGLNK, residues 263-272) selected multiple TCR clonotypes. By dissection of the bulk KK10-specific CTL compartment, differential potency and breadth of KK10-specific CTL clones to inhibit HIV-1 replication was defined due to the distinct TCR usage. Superior control of viral replication of wild-type HIV-1 isolates was observed by the TCR-clonotypic CTLs characteristic of higher ability to produce MIP-1 $\beta$. A unique TCR-equipped KK10- specific CTLs efficiently controlled wide-type HIV-1 isolates and broadly cross-recognized viral variants. These data suggest that clonally diverse CTL responses to a viral epitope increase the likelihood that multiple divergent strains of viruses may be recognized by cross-reactive CTLs through immunization with only a single viral epitope sequence.
\end{abstract}

Keywords: HIV-1; Cytotoxic T-lymphocytes; T cell receptor

\section{Introduction}

Induction of HIV-1-specific CD8+ cytotoxic T lymphocytes (CTLs) is associated with a decline in plasma viremia following acute infection, but neither the magnitude nor breadth of these responses, as measured by IFN- $\gamma$ expression, is correlated with disease control [1-3]. Recent data suggest that other measures of $\mathrm{T}$ cell function, such as proliferation or simultaneous expression of multiple cytokines following peptide stimulation, may better identify effective CTLs [4-7]. None of these strategies, however, assess the ability of CTLs to recognize and kill virus-infected cells. Indeed, the properties currently measured may simply reflect the level of viremia, rather than reveal causes of immune control.

CTLs recognize short peptide fragments of 8-12 amino acids (epitopes) derived from viral proteins presented by class I HLA alleles on the surface of infected cells. The synapse composed of peptide/HLA class I complex and TCR is the key structure between effectors and target cells that defines antigen recognition and functional potential. A critical qualifying component of the virus-specific CTL response is the selection of CTL-bearing TCR that recognize epitopes presented on the infected target cells [8-11]. Epitope-specific CTLs in HIV/ SIV infection are clonally diverse [12-16]. Recent studies of viral suppression by CTL clones derived from SIV-infected monkeys have shown marked differences in activity among multiple clones specific for the same epitopes, and that in vitro suppression of virus replication does not correlate with the ability to produce IFN- $\gamma$, TNF- $\alpha$ or IL-2 [17]. Furthermore, studies from SIV infection [18] has demonstrated that viral escape abrogated the ability of epitope-specific CTLs to control viral replication although IFN- $\gamma$ ELISPOT and IFN- $\gamma / \mathrm{TNF}$ $-\alpha$ ICS assays detected cross-reactivity of those CTLs against the same escape epitope variants. Most of current studies in humans measure the ability of uninfected cells pulsed with supra-physiologic concentrations of synthetic viral peptide to trigger cytokine production by $\mathrm{T}$ cells, and thus fail to account for differences that may be associated with antigen processing and presentation $[19,20]$ and kinetics of $\mathrm{T}$ cell lysis in relation to new progeny virion production [21]. Identifying functional differences between TCR variants that recognize the same HLA/ peptide complex will require direct examination of the interaction between T cells and live HIV-1-infected cells, which has never been comprehensively analyzed.

We have developed a robust in vitro viral inhibition assay that allows identification of CTLs that control HIV-1 replication in autologous CD4 $\mathrm{T}$ cells [22]. This approach incorporates numerous steps that influence virus replication in vivo, including viral entry, antigen processing, epitope presentation, epitope recognition by CD8 T cells, infected cell lysis, and subsequent spread of infection to uninfected cells. We have further demonstrated that TCR clonotypes modulate CTL function against HIV-1 infection by lytic granule loading and delivery after TCR and HLA/peptide engagement [23]. Our current data, employing the viral inhibition assay that measures the relative antiviral efficacy of multiple CTL clones specific for the same epitope from the same HIV1 infected subject, indicate differential antiviral efficacy of CTL clones due to the distinct TCR usage and ability to produce MIP- $1 \beta$.

\section{Materials and Methods}

\section{Study subjects}

HIV-1 infected individuals were recruited from outpatient clinics at local hospitals, following institutional review board approval and written informed consent.

\section{Viruses}

In addition to the CXCR4-utilizing HIV-1 strain NL4-3, the primary isolate X4 $92 \mathrm{HT} 599$ and the primary CCR5-utilizing HIV-1

${ }^{*}$ Corresponding author: Dr. Huabiao Chen, Jiangsu Key Laboratory of Clinical Laboratory Medicine, Jiangsu University School of Medicine, Zhenjiang, Jiangsu 212013, China, Tel: 86-25-4542419; E-mail: chenhuabiao@hotmail.com

Received September 29, 2017; Accepted October 05, 2017; Published October 12,2017

Citation: Tu T, Zhou X, Li T, Jin C, Chen H (2017) Differential Potency and Breadth of the Same Epitope-Specific CTLs to Inhibit HIV-1 Replication based on TCR Usage. J AIDS Clin Res 8: 735. doi: 10.4172/2155-6113.1000735

Copyright: (c) 2017 Tu T, et al. This is an open-access article distributed under the terms of the Creative Commons Attribution License, which permits unrestricted use, distribution, and reproduction in any medium, provided the original author and source are credited. 
strain R5 91US056, were obtained from the AIDS Research and Reagent Program, Division of AIDS, NIAID, NIH (Bethesda, Maryland, USA). HIV-1 laboratory strain NL4-3 was also modified to express one or more mutations in Gag p24 as previously described [24].

\section{Elispot assay}

IFN- $\gamma$ enzyme-linked immunospot (Elispot) assays were performed as described, using optimally defined epitopes [1]. Input cells ranged from 10,000 to 100,000 . To calculate the number of specific spot-forming cells (SFC), the number of spots in the negative control wells was subtracted from the counted number of spots in each well. The magnitude of epitope-specific response was calculated as SFC per million cells.

\section{Generation of CTL clones}

CTL clones were isolated by limiting dilution as previously described [25], using the CD3-specific mAb $12 \mathrm{~F} 6$ as a stimulus for T-cell proliferation. Developing clones were screened for HIV-1-specific CTL activity by a chromium-51 release assay against EBV-transformed autologous B lymphoblastoid cell lines (B-LCL) pulsed with the target peptide. HIV-1-specific clones were maintained by stimulation every 14 to 21 days with an anti-CD3 MAb and irradiated allogeneic PBMC in RPMI 1640 medium containing $50 \mathrm{U} / \mathrm{ml}$ of IL-2.

\section{Quantitative RT-PCR}

Cloned CTLs were stimulated with CD3/CD28 antibodies at $0.5 \mu \mathrm{g} /$ $\mathrm{ml}$ for $24 \mathrm{~h}$. The same amount of cells for each clone was collected in RLT lysis buffer (Qiagen) and extracted total RNA using the RNeasy Mini kit (Qiagen). cDNA was prepared from $1 \mu \mathrm{g}$ of total RNA, using $2 \mu \mathrm{M}$ oligo dT primer and MultiScribe RT enzyme (Applied Biosystems Inc) at $42^{\circ} \mathrm{C}$ for $60 \mathrm{~min}$. Expression was analyzed by mixing cDNA with $100 \mathrm{nM}$ genespecific primers designed to span an exon/exon boundary and Brilliant II SYBR green Q-PCR mix (Stratagene). Products were amplified for 40 cycles on an Mx3005P real time thermocycler (Stratagene). PCR results were normalized to the housekeeping gene HPRT.

\section{TCR $\alpha$ and $\beta$ chain sequencing}

Cloned CTLs were stained with fluorophore-labeled HLA pentamers refolded with epitopic HIV-1 peptides (ProImmune, Oxford, $\mathrm{UK}$ ) and fluorophore-labeled anti-CD8 and CD3 antibodies. Tetramerpositive CD8-positive cells were sorted on a FACS Aria cell-sorting instrument (BD Biosciences) at 70 pounds per square inch (PSI). mRNA was extracted from tetramer-positive CD8-positive $T$ cells using the RNeasy mini kit (Qiagen, Valencia, CA). Anchored RT-PCR was then performed using a modified version of the SMART (switching mechanism at 5 ' end of RNA transcript) procedure and a TCR $\alpha$ or $\beta$ chain constant region 3'-primer to obtain PCR products containing the $\mathrm{V} \alpha$ or $\beta$ chain in addition to the CDR3 region, the Ja/ $\beta$ region and the beginning of the $C \alpha / \beta$ region. Briefly, reverse transcription was carried out at $42^{\circ} \mathrm{C}$ for $90 \mathrm{~min}$ with primers provided for the 5 '-RACE reaction in a SMART-RACE PCR kit (BD Biosciences). First and second round PCR were then performed using a universal 5 '-end primer (5'-CTAATACGACTCACTATAGGGC-3') and nested gene-specific 3'end primers annealing to the constant region of the TCR

$\alpha$ or $\beta$ chain (Ca outer: GTC CATAGACCTCATGTCTAGCACAG;

Ca inner: ATACACATCAGAATCCTTACTTTG;

C $\beta$ outer: 5'-TGTGGCCAGGCACACCAGTGTGGCC-3';

C $\beta$ inner: 5'-GGTGTGGGAGATC158 TCTGCTTCTGA-3').
PCR reaction conditions were as follows: First run: [ $\left[95^{\circ}\right.$ for $30 \mathrm{~s}, 72^{\circ}$ for $2 \mathrm{~min}$ ] for $5 \mathrm{cycles}$, [ $95^{\circ}$ for $30 \mathrm{~s}, 70^{\circ}$ for $30 \mathrm{~s}, 72^{\circ}$ for $2 \mathrm{~min}$ ] for 5 cycles, [ $95^{\circ}$ for $30 \mathrm{~s}, 60^{\circ}$ for $30 \mathrm{~s}, 72^{\circ}$ for $1 \mathrm{~min}$ ] for 25 cycles. Second run: [ $95^{\circ}$ for $30 \mathrm{~s}, 60^{\circ}$ for $30 \mathrm{~s}, 72^{\circ}$ for $1 \mathrm{~min}$ ] for 30 cycles. The PCR product was ligated into the TOPO TA cloning vector (Invitrogen, Carlsbad, CA) and used to transform Escherichia coli (Mach 1, Invitrogen). Colonies were selected, amplified by PCR with M13 primers and sequenced by T7 or T3 primers on an ABI 3100 PRISM automated sequencer. Sequences were edited and aligned using Sequencher (Gene Codes Corp., Ann Arbor, MI) and Se-Al (University of Oxford, Oxford, UK) and compared to the human TCR genes database (http://imgt.cines. fr: $8104 /$ home.html). The TCR V $\alpha / \beta$ chain classification system used is that of the international ImMunoGeneTics database (IMGT) [26].

\section{Flow cytometry}

Cell staining was performed as previously described [4]. Briefly, cells were stained with HLA-B ${ }^{\star} 2705$ KK10 pentamers (ProImmune, Oxford, UK) for $20 \mathrm{~min}$ at room temperature. Following one wash with PBS containing $1 \%$ FCS, the cells were stained with surface antibodies. After 30 min of staining at room temperature, the cells were washed and fixed using the Cytofix/Cytoperm kit (BD PharMingen) according to instructions. Following fixation, the cells were washed twice in the perm buffer and stained with antibodies against intracellular markers. Following staining, the cells were re-suspended in PBS containing 2\% Paraformaldehyde. The Cells were acquired on a LSRII cytometer (BD Biosciences). Flow data were analyzed with the FlowJo software package (Treestar, Ashland, OR).

\section{Viral inhibition assay}

Inhibition of viral replication was assessed in a previously established assay system $[21,22]$. Primary CD4+ T cells were generated from freshly isolated PBMC by the addition of CD3:CD8 bi-specific monoclonal antibody $[27,28]$ or by positive selection with anti-CD4 antibody-coated beads [29]. Greater than $95 \%$ of these primary cells co-expressed CD3 and CD4 by flow cytometric analysis. These CD4+ T cells were stimulated with PHA at $1 \mu \mathrm{g} / \mathrm{ml}$ and infected at day 3 with the designated HIV-1 isolates at a multiplicity of infection (MOI) 0.1 or as otherwise specified for $4 \mathrm{~h}$ at $37^{\circ} \mathrm{C}$, washed twice, resuspended in medium, and plated at $5 \times 10^{5}$ cells per well in a 24 -well plate. To assess inhibition, effector cells then were added at a ratio of 1:1 or as otherwise specified in a total $2 \mathrm{ml}$ of medium in presence of IL-2 at $50 \mathrm{U} / \mathrm{ml}$. At 2 to 4 day intervals, the co-cultures were fed by removing and replacing one-half of the culture supernatant with fresh medium. The removed supernatant was cryopreserved for later p24 antigen quantitation by a standard quantitative enzyme-linked immunosorbent assay (commercial kit (Dupont, Boston, MA). Log inhibition units were calculated as $-\log _{10}(\mathrm{p} 24$ with CTL/p24 without CTL) at day seven in culture.

\section{Results}

\section{$B^{\star 27-K K 10-s p e c i f i c ~ C T L s ~ c o n t r i b u t e ~ t o ~ t h e ~ c o n t r o l ~ o f ~ v i r u s ~}$ replication}

An HLA-B ${ }^{\star} 2705$-positive HIV-1 infected subject (Table 1 ) has been able to maintain a plasma viral load below the limit of detection for decades in the absence of antiretroviral therapy. The CTL response in this subject is characteristic of a dominant immune response targeting the KK10 epitope (KRWIILGLNK, residues 263-272) in p24 Gag (Figure 1a). We first assessed the antiviral function of KK10-specific CD8+ T cells in this subject by comparison of antiviral efficacy of bulk 


\begin{tabular}{|c|c|c|c|c|c|}
\hline HLA & Autologous viral sequence & pVL & CD4 count & TCR $\beta$ chain & Frequency (\%) \\
\hline & (B27-KK10 Gag 263-272) & (copies $/ \mathrm{ml}$ ) & (cells/ul) & & \\
\hline$A^{*} 0301 / 2601$ & provirus KRWIILGLNK & $<50$ & 717 & V $\beta$ 15-CATSETGTTLEQY-J2.7 & 33 \\
\hline$B^{*} 1501 / 2705$ & plasma KRWIIMGLHK & & & VB 6.5-CASSYSRGRTYEQY-J2.7 & 15 \\
\hline \multirow[t]{4}{*}{$\mathrm{Cw}^{*} 0202 / 0303$} & & & & Vß 7.8-CASSLSWRGGYEQY-J2.7 & 7 \\
\hline & & & & Vß 4.3-CASSQGMRAQGYT-J1.2 & 30 \\
\hline & & & & V $\beta$ 28-CATTGGDRNTGELF-J2.2 & 4 \\
\hline & & & & Vß 20.1-CSARTVYQETQY-J2.5 & 11 \\
\hline
\end{tabular}

Table 1: Patient characteristics and TCR repertoire of B27-KK10-specific CD8 T cell populations.
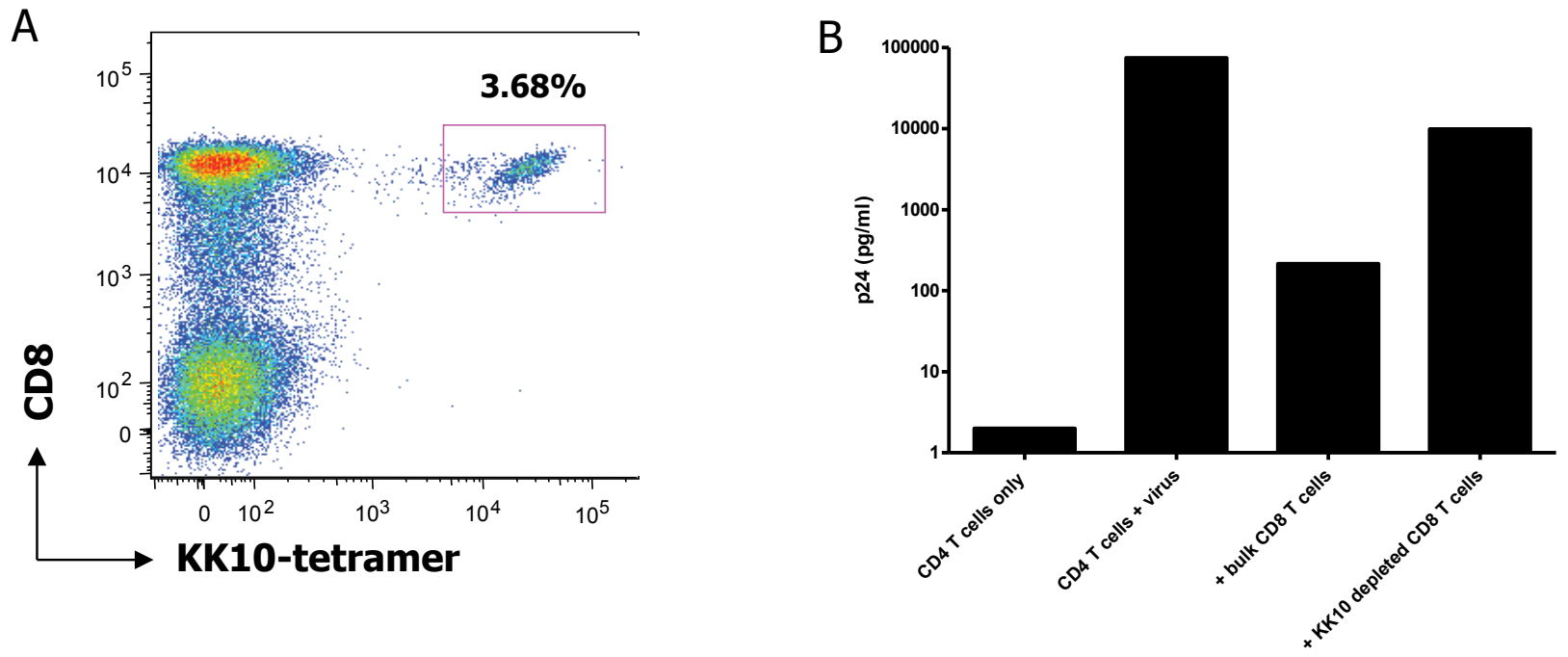

Figure 1: $B^{\star} 27-K K 10$-specific CD8 T cell responses contribute to the control of virus replication. (A) Flow cytometry showed HLA-B*2705 KK10 tetramer-positive cell population from gated CD3+CD8+ lymphocytes in PBMCs of the study subject. (B) Production of p24 antigen in virally infected autologous CD4+ T cells was evaluated in the absence or presence of ex vivo isolated bulk CD8+ T cells or KK10-tetramer-depleted CD8+ T cells at a 1:1 ratio of CD8+ to CD4+ T cells during a 7 day period. The control of virally uninfected CD4+ T cells showed that there were no antologous viruses grown out from the tested subjects during the period of the assay.

CD8+ T cells and KK10-tetramer-depleted CD8+ T cells to inhibit virus replication using our well-established virus inhibition assay [22]. We evaluated the production of p 24 antigen in virally infected autologous CD4+ T cells in the presence of ex vivo isolated bulk CD8+ $\mathrm{T}$ cells or KK10-tetramer-depleted CD8+ T cells. Bulk CD8+ T cells were potent to inhibit virus replication in autologous CD4+ T cells whereas depletion of KK10-specific CTLs by tetramer-sorting resulted in $>95 \%$ of reduction of inhibition (Figure 1b). These data suggest that the KK10-specific CTLs in this subject contribute to the control of virus replication in vivo.

\section{Differential antiviral efficacy of CTL clones based on TCR us- age}

The TCR repertoire of this subject was determined by a detailed molecular analysis of TCR beta gene expression within KK10-specific CD8+ T-cell populations from KK10-tetramer-sorting, showing that the KK10-specific CD8 T-cell compartment of this subject was comprised of multiple clonotypes (Table 1 ). To examine the impact of TCR clonotypes on CTL function, nine HLA B ${ }^{\star} 27-$ KK10-specific CD8 T-cell clones were successfully established by limiting dilution from this subject using a CD3-specific monoclonal antibody as a stimulus for $\mathrm{T}$ cell proliferation [25]. These clones had comparable potency in IFN- $\gamma$ production by Elispot and comparable killing in cytotoxicity assays with exogenous peptide-pulsed autologous B- lymphoblastoid cell lines (B-LCL) (Figures 2a and 2b). We next tested the ability of these clones to inhibit HIV-1 replication in exogenously infected autologous CD4+
$\mathrm{T}$ cells and observed significant variation in the ability to suppress viruses (Figure $2 \mathrm{c}$ ). The clonality was determined by TCR sequencing and showed that these nine $\mathrm{B}^{\star} 27-\mathrm{KK} 10$-specific CD8+ T-cell clones comprised four clonotypes (Figure $2 \mathrm{~d}$ ). Moreover, differential antiviral efficacy was defined due to the distinct TCR usage. The most powerful clones are those equipped with TCR V $\beta 4.3$ and V $\beta 15$ whereas the least inhibition was observed in the clones equipped with TCR V $\beta 20.1$.

\section{Superior inhibition of virus replication by CTL clones secret- ing MIP-1 $\beta$}

To address the possibility that antiviral efficacy was regulated by exhaustion or activation-related genes, using quantitative RT-PCR methods, we evaluated a panel of T-cell exhaustion or activation-related genes (PD-1, CTLA-4, KLRG1, GRAIL, Itch and Cbl-b) for these TCRclonotypic clones after stimulation with $\mathrm{CD} 3 / \mathrm{CD} 28$ antibodies. There was no significant difference of these markers at mRNA levels among these TCR clonotypic clones (Figure 3a). Together, the data indicate that these regulatory protens are not a factor here affecting the antiviral efficacy of the CTL clones and that antiviral efficacy of the same epitope-specific CTLs is determined by TCR clonotypes. The ability of the TCR to initiate and sustain intracellular signal transduction events is essential to ensure productive T-cell activation and induction of antiviral activities [30,31]. To define the possible mechanisms responsible for these differences among the TCR clonotypes, we evaluated a panel of cytokine production (CD107a, IFN- $\gamma$, IL-2, MIP$1 \beta$, and TNF- $\alpha$ ) for these clones by flow cytometry (Figure $3 b$ ). All these 


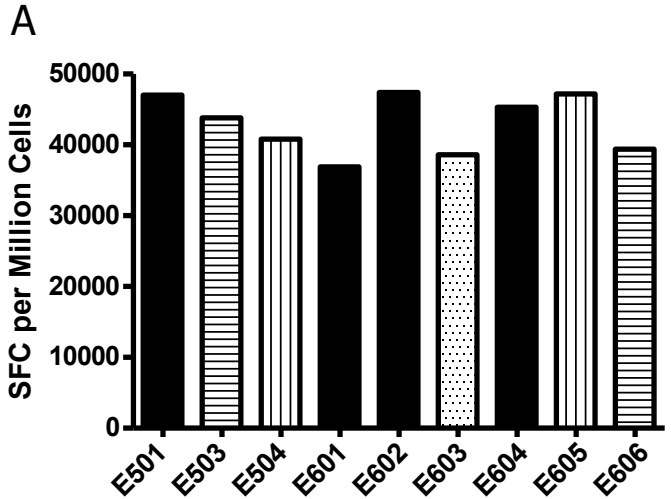

C

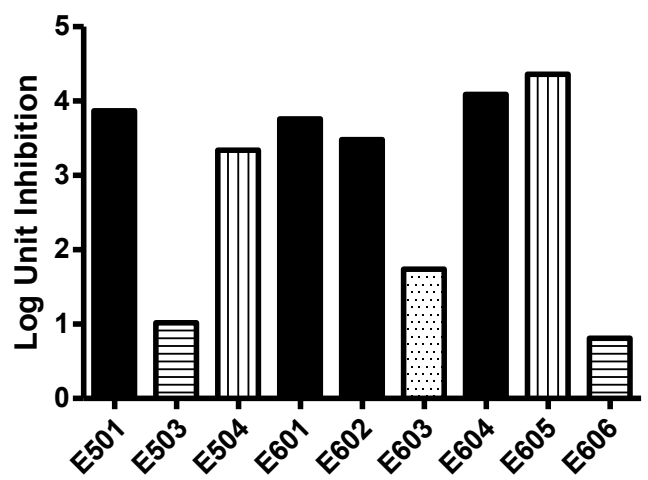

B

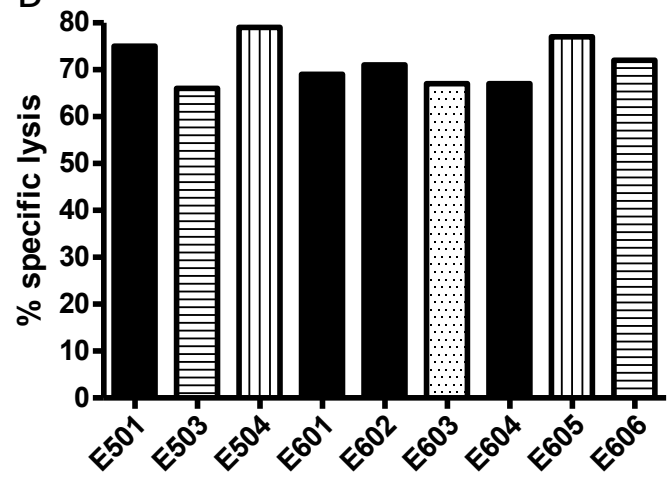

$\mathrm{D}$

\begin{tabular}{|c|c|c|c|}
\hline Clone & $\mathrm{V}$ region & CDR & $\mathrm{J}$ region \\
\hline E501 & $\begin{array}{l}\text { V } \beta 15 \\
V_{a} 14\end{array}$ & $\begin{array}{l}\text { CATSETGTTLEQY } \\
\text { CAMREVSSGNTGKLI }\end{array}$ & $\begin{array}{r}\mathrm{J} 2.7 \\
\mathrm{~J} 37\end{array}$ \\
\hline E503 & $\begin{array}{l}V_{\beta} 20.1 \\
V_{\alpha} 17\end{array}$ & $\begin{array}{l}\text { CSARTVYQETQY } \\
\text { CATDGGLNTNAGKST }\end{array}$ & $\begin{array}{r}\mathrm{J} 2.5 \\
\mathrm{~J} 27\end{array}$ \\
\hline E504 & $\begin{array}{l}V_{\beta 4} .3 \\
V_{\alpha} 14\end{array}$ & $\begin{array}{l}\text { CASSQGMRAQGYT } \\
\text { CAMREPFFGKST }\end{array}$ & $\begin{array}{c}\mathrm{J} 1.2 \\
\mathrm{~J} 27\end{array}$ \\
\hline E601 & $\begin{array}{l}V_{\beta} 15 \\
V_{a} 14\end{array}$ & $\begin{array}{l}\text { CATSETGTTLEQY } \\
\text { CAMREVSSGNTGKLI }\end{array}$ & $\begin{array}{r}\mathrm{J} 2.7 \\
\mathrm{~J} 37\end{array}$ \\
\hline E602 & $\begin{array}{l}\text { V } \beta 15 \\
V_{a} 14\end{array}$ & $\begin{array}{l}\text { CATSETGTTLEQY } \\
\text { CAMREVSSGNTGKLI }\end{array}$ & $\begin{array}{r}\mathrm{J} 2.7 \\
\mathrm{~J} 37\end{array}$ \\
\hline E603 & $\begin{array}{l}\text { V } \beta 7.8 \\
V a 8.3\end{array}$ & $\begin{array}{l}\text { CASSLSWRGGYEQY } \\
\text { CAVGARAAGNKLT }\end{array}$ & $\begin{array}{r}\mathrm{J} 2.7 \\
\mathrm{~J} 17\end{array}$ \\
\hline E604 & $\begin{array}{l}V_{\beta 15} \\
V_{a 14}\end{array}$ & $\begin{array}{l}\text { CATSETGTTLEQY } \\
\text { CAMREVSSGNTGKLI }\end{array}$ & $\begin{array}{r}\mathrm{J} 2.7 \\
\mathrm{~J} 37\end{array}$ \\
\hline E605 & $\begin{array}{l}V_{\beta 4} .3 \\
V_{a} 14\end{array}$ & $\begin{array}{l}\text { CASSQGMRAQGYT } \\
\text { CAMREPFFGKST }\end{array}$ & $\mathrm{J} 1.2$ \\
\hline E606 & $\begin{array}{l}V_{\beta 20.1} \\
V_{\alpha} 17\end{array}$ & $\begin{array}{l}\text { CSARTVYQETQY } \\
\text { CATDGGLNTNAGKST }\end{array}$ & $\begin{array}{r}\mathrm{J} 2.5 \\
\mathrm{~J} 27\end{array}$ \\
\hline
\end{tabular}

Figure 2: CD8+ T-cell clones differ in antiviral efficacy due to TCR usage. (A, B, and C) B*27-KK10-specific CTL clones were tested in a standard IFN-ץ Elispot assay (A), a $4 \mathrm{~h}$ chromium release assay with peptide-pulsed autologous B-LCL targets (B), and a viral inhibition assay using autologous CD4+ T cells infected with the primary X4 HIV-1 isolate (C). Data are expressed as log unit inhibition, calculated as $-\log _{10}$ (p24 with CTL/p24 without CTL) at day seven in culture. (D) The clonality of each clone was determined by TCR sequencing as described in Materials and Methods.

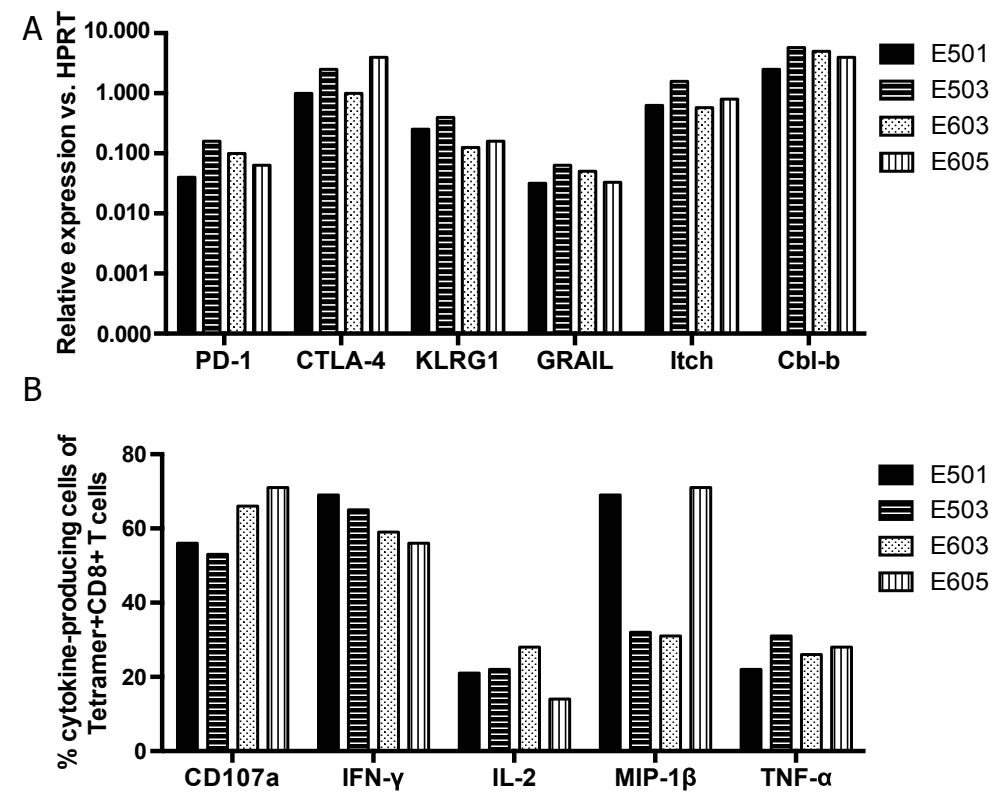

Figure 3: Superior inhibition of virus replication by CTL clones secreting MIP-1 $\beta$. (A) A panel of T-cell exhaustion or activation-related gene expression was evaluated using quantitative RT-PCR after stimulation with CD3/CD28 antibodies for $24 \mathrm{~h}$. PCR results were normalized to the housekeeping gene HPRT. (B) A panel of cytokine production was evaluated by flow cytometry after stimulation with KK10 peptides. Data are expressed as the percentage of cytokine-producing cells out of tetramer+CD8+ cell population. 
Citation: Tu T, Zhou X, Li T, Jin C, Chen H (2017) Differential Potency and Breadth of the Same Epitope-Specific CTLs to Inhibit HIV-1 Replication based on TCR Usage. J AIDS Clin Res 8: 735. doi: 10.4172/2155-6113.1000735

Page 5 of 7

TCR clonotypic KK10-specific CTLs had the similar profile of secretion of IFN- $\gamma$, TNF- $\alpha$, and IL-2 and expression of CD107a after stimulation with KK10 peptides. They were inefficient to produce intracellular IL-2 and TNF- $\alpha$ but comparably competent to secrete intracellular IFN- $\gamma$ and express CD107a. In addition, clone E501 with TCR V $\beta 15$ and clone E605 with TCR V $\beta 4.3$ had significantly high ability to produce intracellular MIP-1 $\beta$ whereas clone E503 with TCR V $\beta 20.1$ and clone E603 with TCR V $\beta 7.8$ were inefficient to produce MIP-1 $\beta$. These data indicate superior inhibition of virus replication by the CTL clones characteristic of high ability to secrete MIP-1 $\beta$ after TCR triggering.

\section{Super control of viral variants by KK10-specific CTL clones with unique TCR}

We next evaluated the production of p24 antigen in autologous $\mathrm{CD} 4+\mathrm{T}$ cells infected by X4 and $\mathrm{R} 5$ viruses harboring KK10 wide-type epitope sequences (Table 2) in the presence or absence of the CTL clones. At a CD8+ to CD4+ T-cell ratio of 1:1 and 1:10, there was essentially complete suppression of both $\mathrm{X} 4$ and $\mathrm{R} 5$ virus replication by the $\mathrm{V} \beta 15$ clone E501 over a 7 day period (Figure 4a). Even at a ratio of $1 \mathrm{CD} 8+\mathrm{T}$ cell per $100 \mathrm{CD} 4+\mathrm{T}$ cells, significant inhibition of virus replication was observed. We next tested the ability of these clones to suppress virus

\begin{tabular}{|c|c|}
\hline Isolate & Gag region amino acid sequence (residues 243-292)a \\
\hline & 272 \\
\hline Consensus & LQEQIGWMTNNPP I PVGEIYKRWIILGLNKIVRMYSPT S ILDIRQGPKEP \\
\hline $\mathrm{X} 4$ & 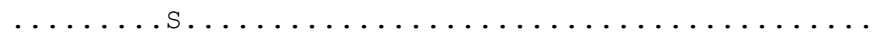 \\
\hline R5 & 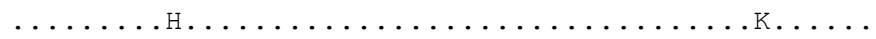 \\
\hline NL4-3 WT & 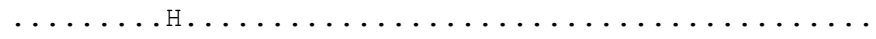 \\
\hline NL4-3 L 6M & 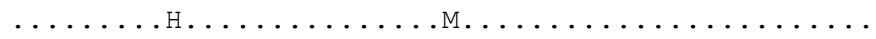 \\
\hline $\mathrm{NL} 4-3 \mathrm{R} 2 \mathrm{~K}$ & 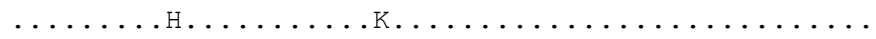 \\
\hline NL4-3 R2KL6M & $\ldots \ldots \ldots$. . . . . . . . . . . . . . . . \\
\hline $\mathrm{NL} 4-3$ SAR2 KL 6M ${ }^{\mathrm{b}}$ & $\ldots \ldots \ldots$. . . . . . . . . . . . . . . . \\
\hline $\mathrm{NL} 4-3 \mathrm{R} 2 \mathrm{~T}$ & $\ldots \ldots \ldots$ нан. \\
\hline NL4-3 R2TL6M & $\ldots \ldots \ldots$. . . . . . . . . . . . . . . . . . . \\
\hline $\mathrm{NL} 4-3 \mathrm{N9H}$ & 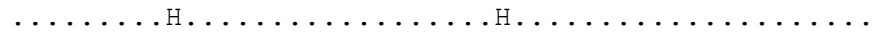 \\
\hline NL4-3 N9HL 6M & 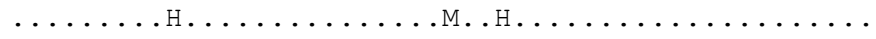 \\
\hline
\end{tabular}

aThe consensus sequence is Consensus B 2002 derived from the Los Alamos HIV sequence database and includes HIV-1 Gag residues 243 to 292

${ }^{\mathrm{b}}$ The constructed viral variant NL4-3 SAR2KL6M contains an upstream $\mathrm{S}_{173}$ A compensatory mutation which can restore impaired replication capacity of the variant NL4-3 R2KL6M [24]

Table 2: HLA-B*27-restricted KK10 epitope sequences (residues 263-272) in HIV-1 strains or viral variants.
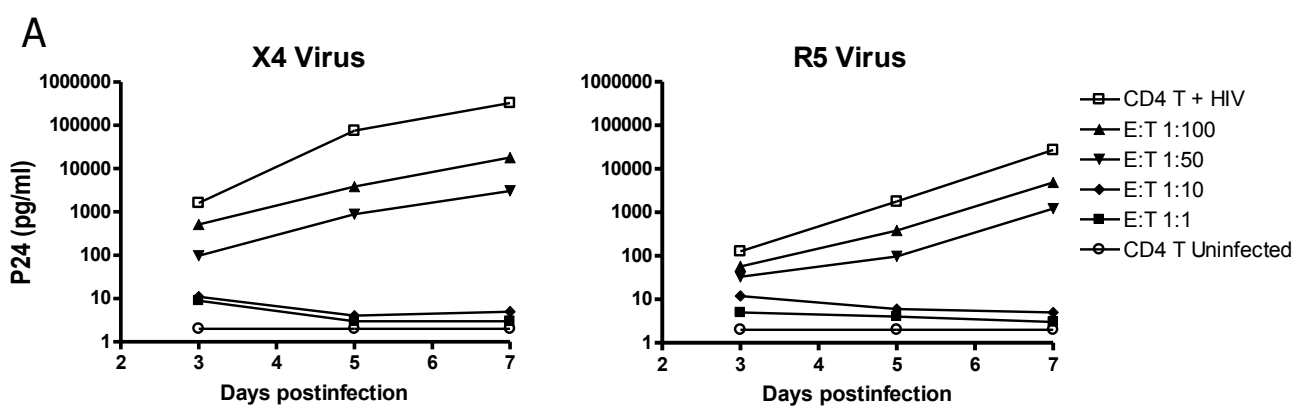

B

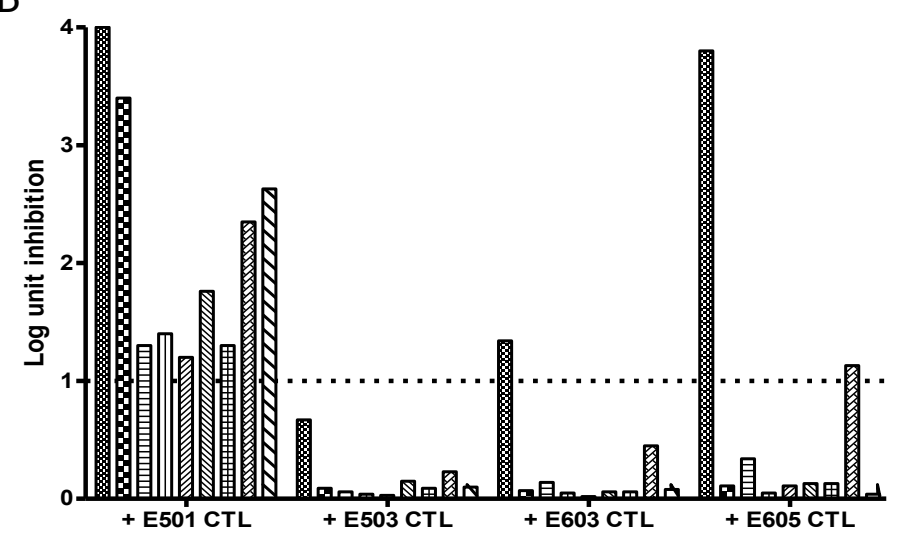

Figure 4: Control of viral variants by KK10-specific CTL clones with unique TCR. (A) Production of p24 antigen in X4- or R5-virally infected autologous CD4+ T cells was evaluated in the presence of V $\beta 15$ clone E501 at indicated ratios of effector to target T cells during a 7-day period. (B) CTL clones were evaluated in the viral inhibition assay using autologous CD4+ T cells infected with NL4-3 wide-type and modified viruses introduced with KK10 epitope sequence variations. Data are expressed as log unit inhibition, calculated as $-\log _{10}$ (p24 with CTL/p24 without CTL) at day seven in culture. 
replication in autologous CD4+ T cells after acute infection of NL43 modified viruses introduced with KK10 epitope sequence variations (Table 2). The V $\beta 15$ clone E501 suppressed viral replication of the NL43 wide-type virus efficiently and cross-recognized the KK10 epitope variant viruses at a wide range (Figure $4 \mathrm{~b}$ ). The discordance in the levels of recognition of variant viruses might be due to replication capacity of these variant viruses, processing efficiency of these variant epitopes and HLA-B ${ }^{\star} 27$ binding affinities for these variant epitope peptides [24]. Likewise, the V $\beta 4.3$ clone E605 efficiently recognized NL4-3 wide-type virus but narrowly recognized $\mathrm{N} 9 \mathrm{H}$ viral variant. These data suggested that MIP- $1 \beta$ was not the factor enable clone E501 to broadly recognize the viral variants since clone E501 and E605 had similarly high ability to produce intercellular MIP-1 $\beta$. The V $\beta 20.1$ clone E503 and V $\beta 7.8$ clone E603 showed inferior recognition of NL4-3 wide-type virus and the least efficacy against the viral variants. Taken together, these data indicate that targeting a single viral epitope by HIV-1-specific CTLs can be highly potent in control of HIV-1 and that control of replication of infecting and mutant strains can be gained by cross-reactive single epitope-specific CTLs equipped with a unique TCR.

\section{Discussion and Conclusion}

The properties of CTLs, such as IFN- $\gamma$ expression, lysis, proliferation, simultaneous expression of multiple cytokines, currently measured following peptide stimulation, have been associated with a decline in plasma viremia but has not been causally linked to viral control $[1,4,5,7]$. Another critical qualifying component of the virus-specific CTLs is the selection of CTL-bearing TCRs that interact with HLA/peptide complex to initiate and sustain intracellular signal transduction events to ensure productive T cell activation and induction of antiviral activities $[30,31]$. Functional differences between TCR variants that recognize the same HLA/peptide complex have not been well defined. In this study, our data show that CTL repertoire specific for HLA-B ${ }^{2} 2705$-restricted HIV1 Gag p24 epitope KK10 (KRWIILGLNK, residues 263-272) in an HIV1 -infected subject who maintains a plasma viral load below the limit of detection for decades without any treatment selected multiple TCR clonotypes. Employing our established in vitro viral inhibition assay that allows direct examination of the interaction between CTLs and live HIV-1-infection autologous CD4+ T cells, our data demonstrate differential antiviral efficacy due to the distinct TCR usage. Importantly, these differences are not detectable using current approaches to assess immune function, including IFN- $\gamma$ ELISPOT assays and cytotoxicity assays with exogenous peptide-pulsed B-lymphoblastoid cell lines. Moreover, these data indicate that control of viral replication could be achieved by unique TCR-quipped epitope-specific CTLs that potently suppress viral replication of HIV-1 harboring the targeted epitopes and broadly cross-recognize viral variants. Measurement of IFN- $\gamma$ secreting capacity does not appear to represent a biologically relevant marker for CTL function in vivo [1-3]. Thus, assays detecting additional $\mathrm{T}$ cell functions are essential to understand qualifying CTLs linked to viral control. Data suggest that the ability of stimulated $\mathrm{T}$ cells to simultaneously produce multiple cytokines (IFN- $\gamma$, TNF- $\alpha$, and IL-2) and to degranulate (i.e., express surface CD107) correlates with disease status better than any of these markers alone [4,7], but this may be a reflection of lower levels of viremia rather than a cause of it. Our data show that all the $\mathrm{B}^{\star} 27-\mathrm{KK} 10$ - specific CTL clones generated from the study subject produce IFN- $\gamma$, TNF- $\alpha$ and IL-2 and express CD107a at the comparable level after stimulation with specific peptides but differ greatly in the ability of suppression of viral replication in vitro due to the distinct TCR usage. Notably, the superior inhibition of viral replication is observed by the clones with additional ability to secrete MIP-1 $\beta$. This result consists with the finding by Freel et al. [32] that the strongest correlation between the potency of antiviral activity and number of HIV-1-specific cells was found for monofunctional cells expressing MIP- $1 \beta$ alone although these cytokines were simultaneously expressed and were coordinately regulated in many CTLs. However, MIP- $1 \beta$ has been directly linked to inhibit infection of CCR5-utilizing HIV-1 by blocking the co-receptor [33]. Here, the comparably competent MIP$1 \beta$-producing V $\beta 4.3$ clone E605 and V $\beta 15$ clone E501 efficiently inhibit viral replication of CXCR4-utilizing wild-type HIV-1. Meanwhile, E501 broadly cross-recognize viral variants of CXCR4-utilizing HIV-1 but E605 narrowly recognize N9H variant. The previous studies examining the ability of CTLs to inhibit CCR5-utilizing HIV-1 JR-CSF strain replication in infected CD4+ cell lines [34] showed that a small portion of the inhibition of HIV-1 is mediated by soluble factors including MIP$1 \alpha$, MIP- $1 \beta$ and RANTES, as well as a distinct factor(s) triggered in an antigen-specific and HLA-restricted fashion but then act without HLA restriction. An earlier study also demonstrated that RANTES, MIP-1 $\alpha$ and MIP- $1 \beta$ did not account for the entire scope of CD8+ T-cell derived HIV-suppressor factors [35]. These data suggest that MIP- $1 \beta$ might represent a biological marker relevant to CTL function rather than a main antiviral factor by blocking the co-receptor.

In addition, numerous regulatory proteins have been reported to induce on T cells during chronic HIV-1 and biologically affect T cell function [36-38]. Here, no difference of expression of a panel of T-cell exhaustion and activation-related genes (PD-1, CTLA-4, KLRG1, GRAIL, Itch and Cbl-b) was observed for these TCR-clonotypic clones, indicating that these regulatory proteins did not account for the differential antiviral efficacy of these clones. Likewise, the capacity of CTLs to proliferate has been associated with long-term nonprogressive HIV-1 infection but also has not been directly linked to viral control [5,7]. These TCR-clonotypic KK10-specific CTL clones were established by limiting dilution using a CD3-specific monoclonal antibody as a stimulus for T-cell proliferation and cultured in a medium with IL-2. They had comparable capacity of proliferation and clonal expansion thus excluded the possibility that proliferation accounted for the differential antiviral efficacy for these clones.

Taken together, our data indicate that differential potency and breadth of recognition of HIV-1 and its mutant strains is defined due to the distinct TCR selected by CTLs targeting the same viral epitope. Moreover, these data suggest that subtle differences in the fine specificity of the CTLs in regard to TCR clonotypes allow crossrecognition of a considerable degree of viral epitope variations that have even not previously been presented to the host immune system which may facilitate the host to control infecting and emergent mutant strains. These findings contribute to the understanding of qualifying CTLs in regard to TCR clonality and suggest that understanding TCR clonal diversity and TCR structural basis of CTL function is particularly important for the HIV-1 T-cell vaccine design and adoptive T-cell therapy.

\section{Acknowledgement}

This work was supported by the Fund for Jiangsu Specially-Appointed Professor (2014JSTPJS-53) and the Innovation Fund from National Center for AIDS/STD Control and Prevention, China CDC.

\section{References}

1. Addo MM, Yu XG, Rathod A, Cohen D, Eldridge RL, et al. (2003) Comprehensive epitope analysis of human immunodeficiency virus type 1 (HIV-1)-specific T-cell responses directed against the entire expressed HIV-1 genome demonstrate broadly directed responses, but no correlation to viral load. J Virol 77: 20812092.

2. Betts MR, Ambrozak DR, Douek DC, Bonhoeffer S, Brenchley JM, et al. (2001) 
Citation: Tu T, Zhou X, Li T, Jin C, Chen H (2017) Differential Potency and Breadth of the Same Epitope-Specific CTLs to Inhibit HIV-1 Replication based on TCR Usage. J AIDS Clin Res 8: 735. doi: 10.4172/2155-6113.1000735

Analysis of total human immunodeficiency virus (HIV)-specific CD4(+) and CD8(+) T-cell responses: Relationship to viral load in untreated HIV infection. J Virol 75: 11983-11991.

3. Edwards BH, Bansal A, Sabbaj S, Bakari J, Mulligan MJ, et al. (2002) Magnitude of functional CD8+ T-cell responses to the gag protein of human immunodeficiency virus type 1 correlates inversely with viral load in plasma. $J$ Virol 76: 2298-2305.

4. Betts MR, Nason MC, West SM, De Rosa SC, Migueles SA, et al. (2006) HIV non-progressors preferentially maintain highly functional HIV-specific CD8+ T cells. Blood 107: 4781-4789.

5. Migueles SA, Laborico AC, Shupert WL, Sabbaghian MS, Rabin R, et al. (2002) HIV-specific CD8+ T cell proliferation is coupled to perforin expression and is maintained in non-progressors. Nat Immunol 3: 1061-1068.

6. Zimmerli SC, Harari A, Cellerai C, Vallelian F, Bart PA, et al. (2005) HIV-1specific IFN-gamma/IL-2-secreting CD8 T cells support CD4-independent proliferation of HIV-1-specific CD8 T cells. Proc Natl Acad Sci U S A 102: 7239 7244.

7. Almeida JR, Price DA, Papagno L, Arkoub ZnAt, Sauce D, et al. (2007) Superior control of HIV-1 replication by CD8+ T cells is reflected by their avidity, polyfunctionality and clonal turnover. J Exp Med 204: 2473-2485.

8. Dong T, Stewart-Jones G, Chen N, Easterbrook P, Xu X, et al. (2004) HIVspecific cytotoxic T-cells from long-term survivors select a unique $T$ cell receptor. J Exp Med 200: 1547-1557.

9. Pantaleo G, Demarest JF, Soudeyns H, Graziosi C, Denis F, et al. (1994) Major expansion of $C D 8+T$ cells with a predominant $V$ beta usage during the primary immune response to HIV. Nature 370: 463-467.

10. Wilson JD, Ogg GS, Allen RL, Goulder PJ, Kelleher A, et al. (1998) Oligoclonal expansions of CD8(+) T cells in chronic HIV infection are antigen specific. J Exp Med 188: 785-790

11. Douek DC, Betts MR, Brenchley JM, Hill BJ, Ambrozak DR, et al. (2002) A novel approach to the analysis of specificity, clonality and frequency of HIVspecific $T$ cell responses reveals a potential mechanism for control of viral escape. J Immunol 168: 3099-3104

12. Charini WA, Kuroda MJ, Schmitz JE, Beaudry KR, Lin W, et al. (2001) Clonally diverse CTL response to a dominant viral epitope recognizes potential epitope variants. J Immunol 167: 4996-5003.

13. Chen ZW, Li Y, Zeng X, Kuroda MJ, Schmitz JE, et al. (2001) The TCR repertoire of an immunodominant CD8+ T lymphocyte population. J Immunol 166: $4525-4533$

14. Killian MS, Sabado RL, Kilpatrick S, Hausner MA, Jamieson BD, et al. (2005) Clonal breadth of the HIV-1-specific T-cell receptor repertoire in vivo as determined by subtractive analysis. Aids 19: 887-896

15. Letvin NL, Yasutomi Y, Shen L, Reimann KA, Chen ZW, et al. (1998) The CD8+ T lymphocyte response during primary SIVmac infection. Adv Exp Med Biol 452: 177-179.

16. Moss PA, Rowland-Jones SL, Frodsham PM, McAdam S, Giangrande P, et al. (1995) Persistent high frequency of human immunodeficiency virus-specific cytotoxic T-cells in peripheral blood of infected donors. Proc Natl Acad Sci U S A 92: 5773-5777.

17. Chung C, Lee W, Loffredo JT, Burwitz B, Friedrich TC, et al. (2006) Not all cytokine-producing CD8+ T-cells suppress simian immunodeficiency virus replication. J Virol 81: 1517-1523.

18. Loffredo JT, Burwitz BJ, Rakasz EG, Spencer SP, Stephany JJ, et al. (2006) SIV-specific CD8+ T cell antiviral efficacy is unrelated to epitope specificity and abrogated by viral escape. J Virol 2006: JVI.01912-06.

19. Valentine LE, Piaskowski SM, Rakasz EG, Henry NL, Wilson NA, et al. (2008) Recognition of escape variants in ELISPOT does not always predict CD8+ T-cell recognition of simian immunodeficiency virus-infected cells expressing the same variant sequences. J Virol 82: 575-581

20. Le Gall S, Stamegna P, Walker BD (2007) Portable flanking sequences modulate CTL epitope processing. J Clin Invest 117: 3563-3575.

21. Yang OO, Kalams SA, Rosenzweig M, Trocha A, Jones N, et al. (1996) Efficien lysis of human immunodeficiency virus type 1-infected cells by cytotoxic $T$ lymphocytes. J Virol 70: 5799-5806.

22. Chen H, Piechocka-Trocha A, Miura T, Brockman MA, Julg BD, et al. (2009)
Differential neutralization of human immunodeficiency virus (HIV) replication in autologous CD4 T cells by HIV-specific cytotoxic T lymphocytes. J Virol 83: 3138-3149.

23. Chen H, Ndhlovu ZM, Liu D, Porter LC, Fang JW, et al. (2012) TCR clonotypes modulate the protective effect of HLA class I molecules in HIV-1 infection. Nat Immunol 13: 691-700.

24. Schneidewind A, Brockman MA, Sidney J, Wang YE, Chen H, et al. (2008) Structural and functional constraints limit options for cytotoxic T-lymphocyte escape in the immunodominant HLA-B27-restricted epitope in human immunodeficiency virus type 1 capsid. J Virol 82: 5594-5605.

25. Walker BD, Flexner C, Birch-Limberger K, Fisher L, Paradis TJ, et al. (1989) Long-term culture and fine specificity of human cytotoxic T-lymphocyte clones reactive with human immunodeficiency virus type 1. Proc Natl Acad Sci U S A 86: 9514-9518.

26. Lefranc MP, Pommie C, Ruiz M, Giudicelli V, Foulquier E, et al. (2003) IMGT unique numbering for immunoglobulin and $T$ cell receptor variable domains and Ig superfamily V-like domains. Dev Comp Immunol 27: 55-77.

27. Wong JK, Hezareh M, Günthard HF, Havlir DV, Ignacio CC, et al. (1997) Recovery of replication-competent HIV despite prolonged suppression of plasma viremia. Science 278: 1291-1295.

28. Wilson CC, Wong JT, Girard DD, Merrill DP, Dynan M, et al. (1995) Ex vivo expansion of CD4 lymphocytes from human immunodeficiency virus type 1 -infected persons in the presence of combination antiretroviral agents. $J$ Infect Dis 172: 88-96.

29. SÃ $j$ ez-Ciri $\tilde{A}^{3} n A$, Lacabaratz C, Lambotte O, Versmisse P, Urrutia A, et al. (2007) HIV controllers exhibit potent CD8 T cell capacity to suppress HIV infection ex vivo and peculiar cytotoxic T-lymphocyte activation phenotype. Proceedings of the National Academy of Sciences 104: 6776-6781.

30. Kane LP, Lin J, Weiss A (2000) Signal transduction by the TCR for antigen. Curr Opin Immunol 12: 242-249.

31. van Leeuwen JEM, Samelson LE (1999) T cell antigen-receptor signal transduction. Curr Opin Immunol 11: 242-248.

32. Freel SA, Lamoreaux L, Chattopadhyay PK, Saunders K, Zarkowsky D, et al (2010) Phenotypic and functional profile of HIV-inhibitory CD8 T cells elicited by natural infection and heterologous prime/boost vaccination. J Virol 84: 49985006.

33. Cocchi F, DeVico AL, Garzino-Demo A, Arya SK, Gallo RC, et al. (1995)

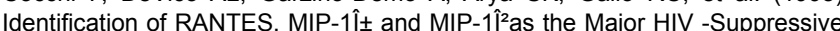
Factors Produced by CD8 $\$^{\wedge}+\$$ T Cells. Science $270: 1811-1815$.

34. Yang OO, Kalams SA, Trocha A, Cao H, Luster A, et al. (1997) Suppression of human immunodeficiency virus type 1 replication by CD8+ cells: Evidence for HLA class I-restricted triggering of cytolytic and non-cytolytic mechanisms. Virol 71: 3120-3128.

35. Moriuchi H, Moriuchi M, Combadiere C, Murphy PM, Fauci AS (1996) CD8+ T-cell- derived soluble ${ }^{2}$ factor(s), but not $\hat{I}$-chemokines RANTES, MIP-1 1 I, and MIP-1 $\hat{\mid}^{2}$, suppress HIV-1 replication€\%omonocyte/macrophagesinâ. Proc Nat Acad Sci U S A 93: 15341-15345.

36. Galiani MD, Aguado E, Tarazona R, Romero P, Molina I, et al. (1999) Expression of killer inhibitory receptors on cytotoxic cells from HIV-1-infected individuals. Clin Exp Immunol 115: 472-476.

37. Kaufmann DE, Kavanagh DG, Pereyra F, Zaunders JJ, Mackey EW, et al. (2007) Upregulation of CTLA-4 by HIV-specific CD4+ T cells correlates with disease progression and defines a reversible immune dysfunction. Nat Immunol 8: 1246-1256.

38. Day CL, Kaufmann DE, Kiepiela P, Brown JA, Moodley ES, et al. (2006) PD-1 expression on HIV-specific T cells is associated with T-cell exhaustion and disease progression. Nature 443: 350-354. 